تأثير اضافة الخل الى ماء الثرب في الاداء الاتتاجي لفروج اللحم خلال فصل الصيف

محمد جعفر باقر الثديدي , شهرزاد محمد جعفر الشديدي” ، نجم اسماعيل الحديثي

$$
\begin{aligned}
& \text { وعمار قعطان الاوسي } \\
& \text { كلية الززاعة /جامعة بغاد التاد }
\end{aligned}
$$

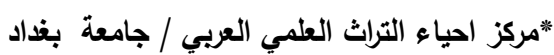

$$
\begin{aligned}
& \text { تأريخ القبول 26/7/2009 } \\
& \text { الخلاصة }
\end{aligned}
$$

اجري البحث في حقل الطيور الداجنة التابع لكلية الزراعة / جامعة بغداد خلال فصل الصيف و للهدة

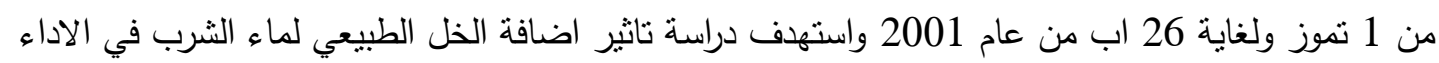

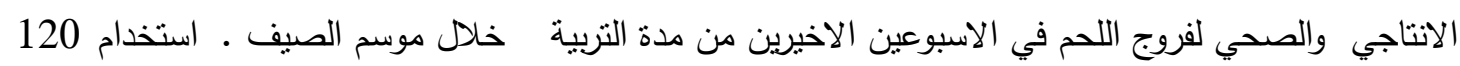

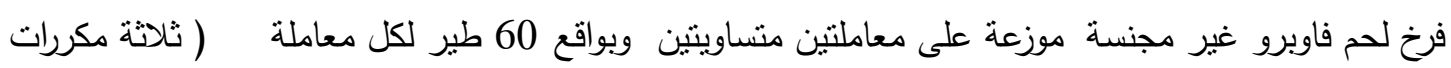

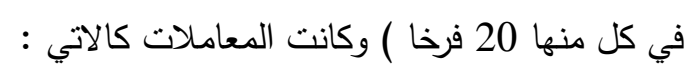

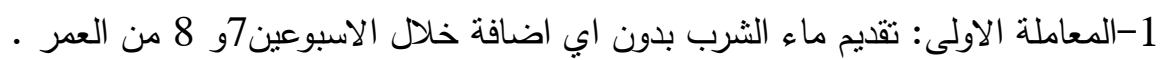

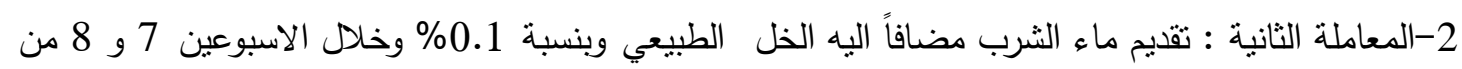

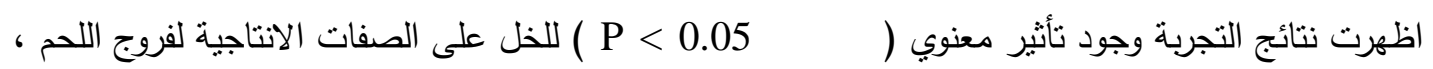

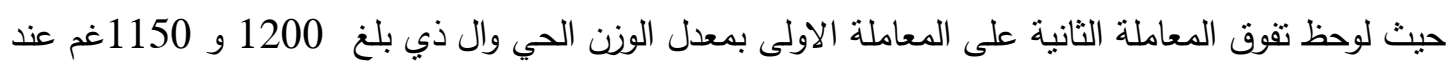

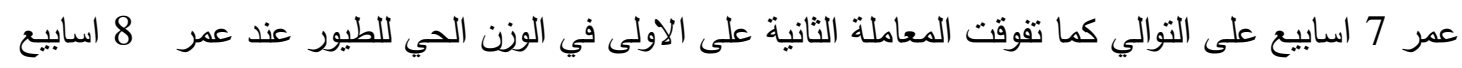

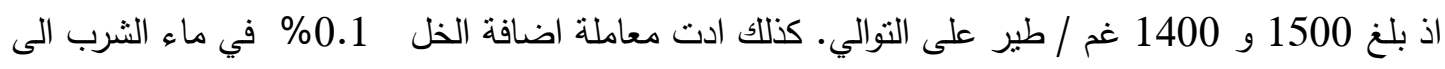

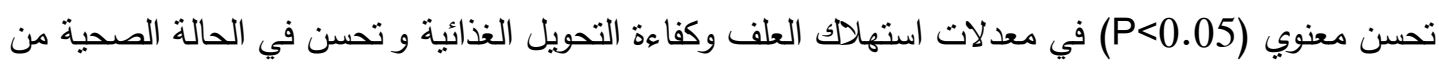

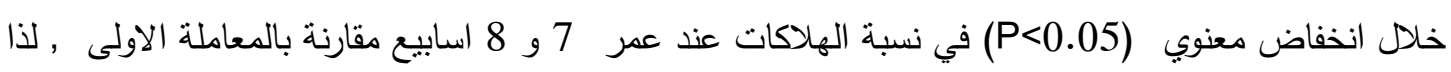

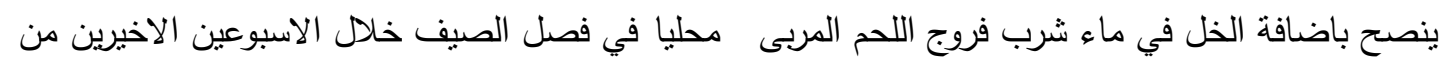

\title{
EFFECT OF VINEGER ADDED TO DRINKING WATER ON THE BROILER PERFORMANCE DURING SUMMER SEASON
}

\author{
Mohammad J.B. Al- Shadeed; Shahrazad M. Al-Shadeed* \\ Najim I. Al-Hadeethi and Ammar. Q. Al-Awssi \\ College of Agriculture, Baghdad University \\ * Arab Scientific Heritage Revival Center, Baghdad University.
}

Summery

This study was conducted at poultry farm of the College of Agriculture, University of Baghdad during the period from the $21^{\text {st }}$ of July to $26^{\text {th }}$ of August of 2001 to 
identify the effects of vineger on broiler performance at the two weeks of breeding period during summer season. One hundred and twenty unsexed faw-bro broiler chicks divided randomly into two equal groups consisted of 60 chicks in each (3 replicate of 20 chicks each ) they were exposed to one of the following treatments:-

- Treatment 1: tap water for the 7 and 8 weeks of age.

- Treatment 2: water + vineger $(0.1 \%)$ for the same period.

The results showed that treat. 2 enhanced significantly $(\mathrm{P}<0.05)$ body weight compared with treat. 1 . The mean body weight were 1200 and $1150 \mathrm{gm}$ at 7 weeks of age and 1500,1400 at 8 weeks of age respectively. Also adding $0.1 \%$ vineger to drinking water improved significantly $(\mathrm{P}<0.05)$ feed intake, feed conversion and decreased mortality at 7 and 8 weeks of age .

\section{المقدمة}

تتتج الجراثيم المجبوة اللاهوائية مثل Lactobacillus و Bifidobacteria الاحماض العضوية في داخل القناة الهضمية للاجاج وخاصة الاعورين مثل حمض اللاكتيك والبروبيونيك والبيوتيريك ( 1 ) عن طريق تخمير المصادر الكاربوهيدراتية مثل السكريات البسيطة كسكر اللاكتوز ( 2 ) ، وقد اتجه الباحثون الى اضافة سكر اللاكتوز في علف الدجاج لتنشيط عمل هذه الاحباء المجهرية المفيدة لانتاج وافراز الاحماض العضوية ( 3) ،

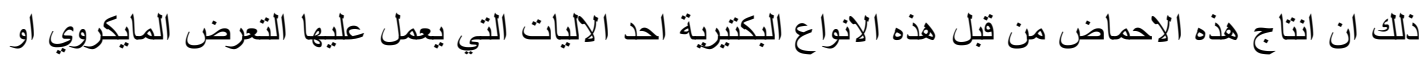

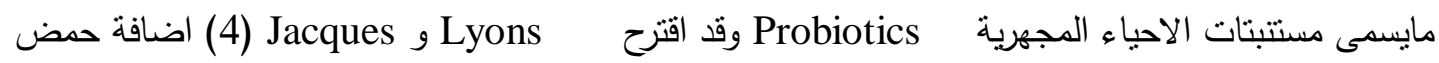
البروبيونيك الى ماء شرب الافراخ لزيادة مقاومتها تجاه المسببات المرضية وبالتالي تحسين الاداء الانتاجي لها ـ الخاء الخل Vineger هو احد المنتجات الغذائية المتوفرة محليا ويحوي على نركيز مرتفع من حمض الخليك Acetic acid ماء الشرب في تخفيف الاجهاد الحراري عن طريق خفض PH الدم (5 ) ) واوصى العاني (6 ) باضافه الخل الى ماء الثرب المقدم لفروج اللحم من اجل تحسين الوزن الحي والكفاءة الانتاجية خلاء فصل الصبف ، وبما ان تاثير الاجهاد الحراري يظهر واضحا في الاعمار المتقدمة لفروج اللحم بسبب ارتفاع الوزن الحي وزيادة

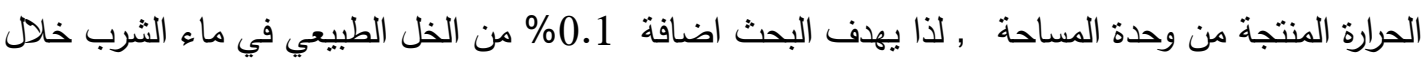

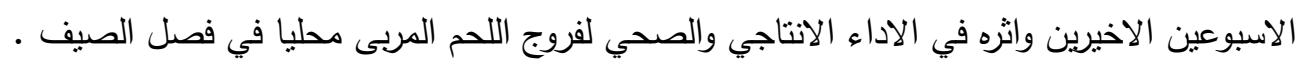

\section{المواد وطرائق العمل}

اجريت هذه الدراسة في حقل الطيور الداجنة - كلية الزراعة - جامعة بغداد الال فصل الصيف وللادة من 1 تموز ولغاية 26 اب من عام 2001 وهي الفترة التي تشهر اعلى درجات الحرارة.

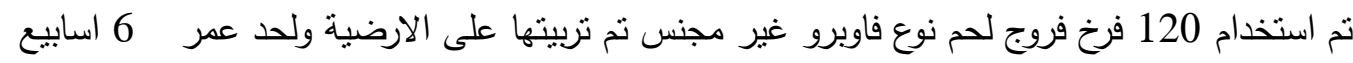

بعد ذلك وزعت عشوائيا على معاملتي التجربة وبواقع 20 طبر لكل مكرر وكانت كل معاملة تشتمل على 3

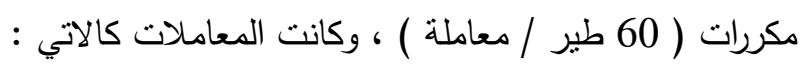

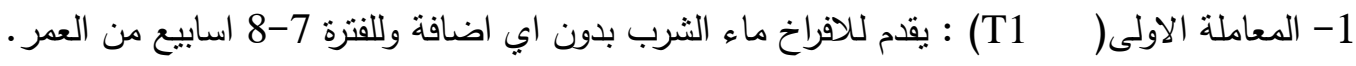

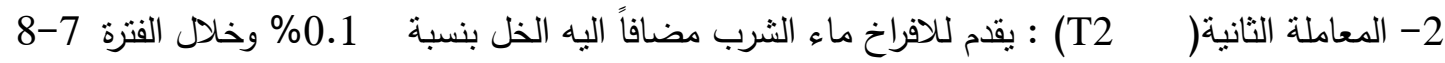

$$
\text { اسابيع من العمر وبصورة مستمرة. }
$$


1 - تغذية الافراخ : استخدم ت عليقة بادىء للمدة 1-3 اسبوع ثم استبدلت بعليقة النهائي للمدة 4-8 اسابيع والجدول (2) يبين مكونات العليقة المستخدمة في تغذية الافراخ خلادل مدة التجربة وتحليلها · الكيمياوي

2 - ماء الثرب : خلط الخل الطبيعي مع ماء الثرب وبنسبة 0.1\% و موزع على المناهل اليدوية المقلوبة سعة 5 لترات وهذه المناهل تمليء لاكثر من مرتين يومياً بعد غسلها بالماء جيداً وتم تجهيز كل مكرر • بمنهلين

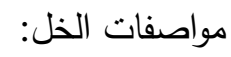
استخدم الخل الطبيعي (خل البدوي ) الناتج من عملية تخمير المواد السكرية الموجودة في التمر والمبين تركيبه الكيمياوي في جدول (3) كما اثنار له الحكيم وحسن ؛ (7).

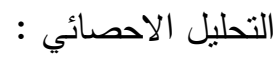

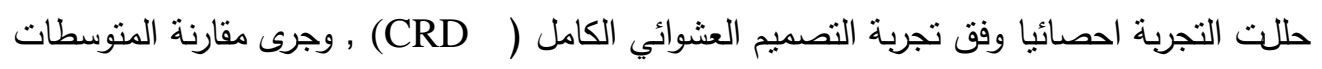
باختبار دنكن متعدد المديات وباستخدام التحليل الاحصائي الجاهز ( 8 ). جدول (2) تركيب العلائق المستخدمة و التحليل الكيميائي لها

\begin{tabular}{|c|c|c|}
\hline نهائي\% & بادى٪\% & 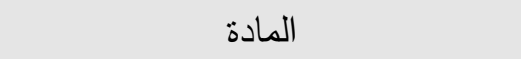 \\
\hline 63 & 54 & ذرة صفراء \\
\hline 16 & 15 & حنطة \\
\hline 12 & 20 & كسبة فول الصويا ( 44\% بروتين) \\
\hline 8 & 10 & مركز بروتيني حيواني ( 50\% بروتين) \\
\hline 0.65 & 0.65 & حجر كلس \\
\hline 0.35 & 0.35 & ملح الطعام \\
\hline 100 & 100 & 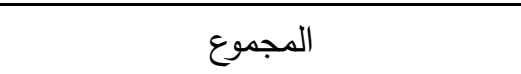 \\
\hline & & التحليل الكيمبائي المحسوب* \\
\hline 19.88 & 23.6 & البروتين ( \% ) \\
\hline 3015 & 2853 & (كيلوسعرة/كغم علف) الطاقة الممتلة \\
\hline 3.72 & 4.5 & الالياف (\% ) \\
\hline 0.65 & 0.7 & الفسفور (\% ) \\
\hline 1.4 & 1.5 & الكالسيوم(\% ) \\
\hline 151.6 & 120.9 & الطاقة : البرونين \\
\hline
\end{tabular}

*حسب التركيب الكيمياوي للعلائق حسب نركيب المواد العلفية الوارد في NRC (9). 


\begin{tabular}{|c|c|}
\hline غم / 100 مل خل & المحتويات \\
\hline 4.0 & حمض الخليك \\
\hline 0.7 & الرماد \\
\hline 3.0 & المواد الصلبة \\
\hline 0.5 & الكحول \\
\hline
\end{tabular}

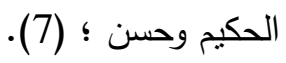

النتائج

تأثنير اضافة الخل على وزن الجسم الحي:

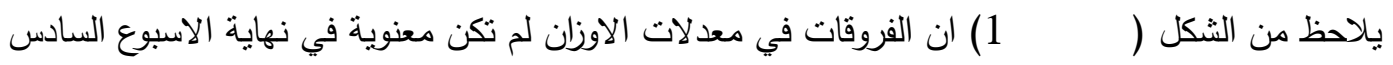

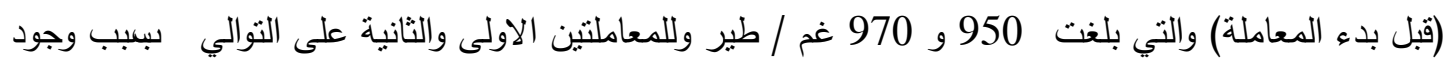

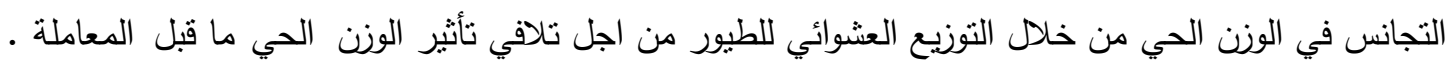

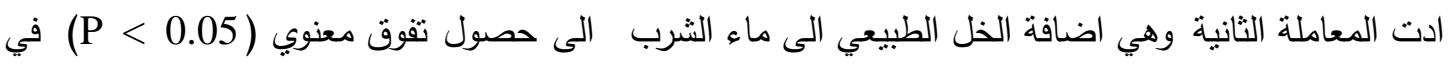

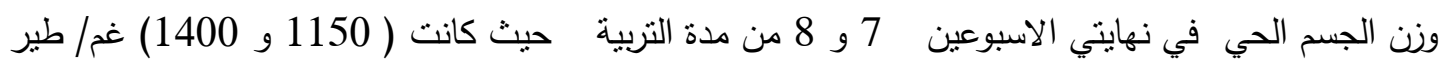

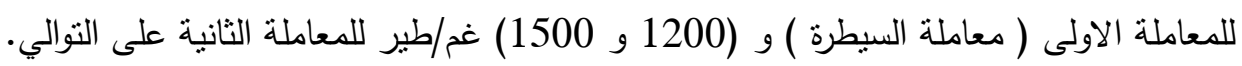
تأثثير اضافة الخل على استهلاك العلف:

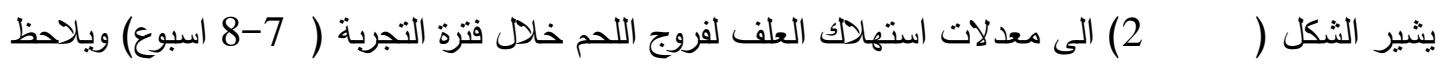

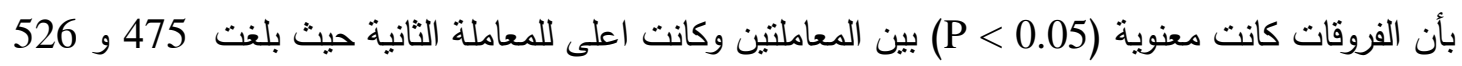

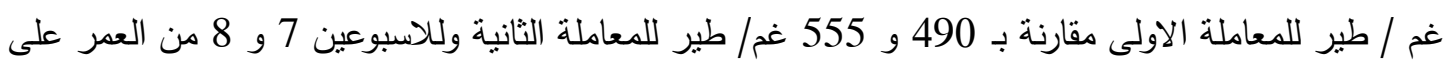
التوالي. تأثير اضافة الخل على كفاءة التحويل الغذائي:

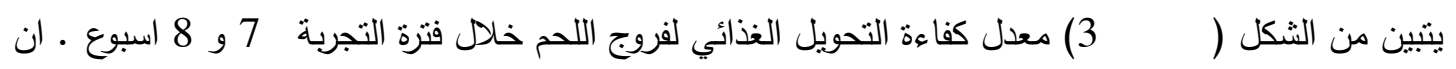
الفروقات كانت معنوية (P (P) بين المعاملتين وكانت افضل للمعاملة الثانية 2.0 .0 و 1.7 مقارنة بـ 2.4 و و

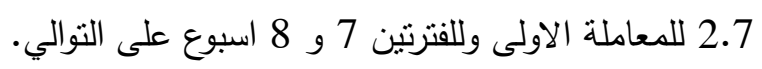
تأثثير اضافة الخل على نسبة الهلاكات:

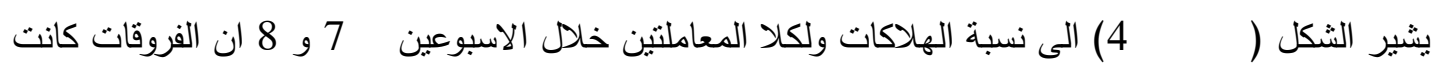
غير معنوية خلال الاسبوع السابع حيث بلغت 1.5 و 1\% وللمعاملتين الاولى والثانية على التوالي ، لكن يلاحظ ان الفروقات كانت معنوية (P 0.05 > P بين المعاملتين خلال الاسبوع الثامن وكانت اقل للمعاملة الثانية حيث بلغت 3\% مقارنة بـ 6\% للاولى ، وكانت الفروقات معنوية ( 0.05 > P) في نسبة الهلاكات الكلية خلال

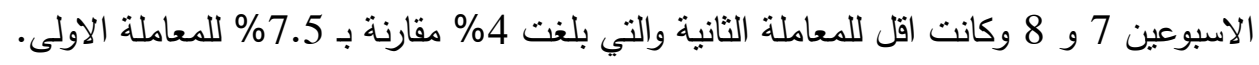

\section{المناقثة}


ان التفوق الحاصل في وزن الجسم الحي في معاملات اضافة الخل الطبيعي في ماء الثرب خلال

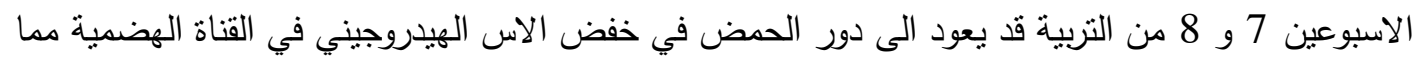

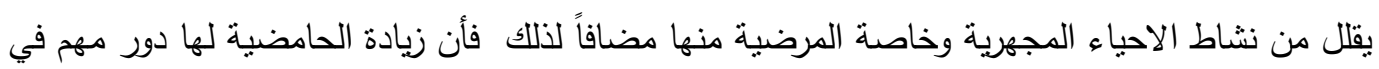

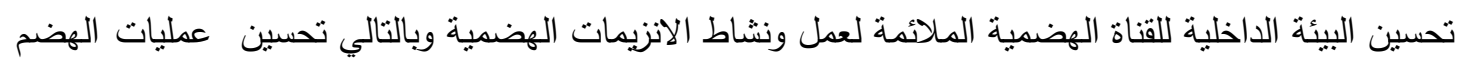
والامتصاص ( 10) وبالتالي تحسن الوزن الحي وبما ان ارتفاع درجات الحرارة صيفاً من المشاكل الرئيسة التي تسبب انخفاض استهلاك العلف من قبل الطيور تلافياً لانتاج الحرارة (11 ) فقه يكون اضافة الخل فئن في ماء

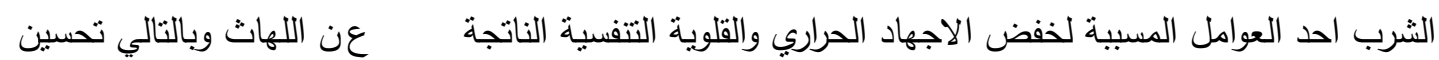
استهلاك العلف اليومي (6 و 12 ) , فضلا عن ذلك فلى الخل قد يعمل على خفض الاجهاد الحراري وتحسين استهلاك العلف وزيادة جاهزية العناصر الغذائية عند انخفاض الاس الهيدروجيني وبالتالي زيادة الاستفادة من

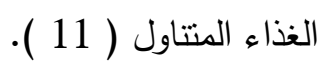

كما ان الاحماض العضوية من شأنها ان تعمل على قتل الاحياء المجهرية الموجودة في القناة الهضمية

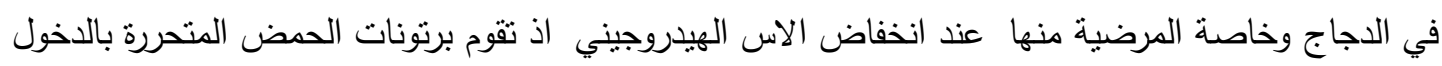
الى داخل الخلية البكتيرية واتلاف نظامها الانزيمي ثم موتها لذا فان خلو القناة الهضمية من هذه الاحياء المجهرية او سمومها يعمل على زيادة الحيوية ويخفض من نسبة الهلاكات( 13 ).

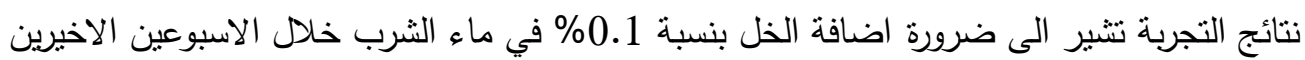

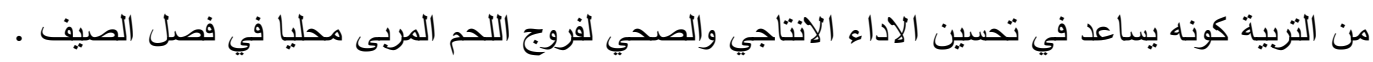
المصادر

1. Barnes E.M. Impey SC and Stern LH (1979). Factor affecting the incidence and anti- Salmonella activite of the anaerobic cecal flora of the young chick J.Hyg Camb 82: 263- 283.

2. Hume ME Corrier DE Nisbet DJ and Deloach JR (1995). Effect of a continuous - flow competitive exclusion culture on cecal and crop colonization by Salmonella typhimurium in broilers at growout. Poultry Sci. 74 (suppl. 1): 154 (Abstr.).

3. Corrier DE Nisbet DJ Scanlan CM Hollister AG and Deloach JR (1995). Control of Salmonella typhimurim colonization in broiler chicks with a contionus - flow characterized mixed culture of cecal bacteria. Poultry Sci. 74: 916-924.

4. Lyons TP and Jacques KA(1998) Biotechnology in the feed industry proc Alltech's $14^{\text {th }}$ Symp. Nottingham university press, Loughborough, Leicesteruk.

5. Phillippe, PH( 1996) . Manging broilers in hot weather, World Poult. Sci. 12 : 29-30 .

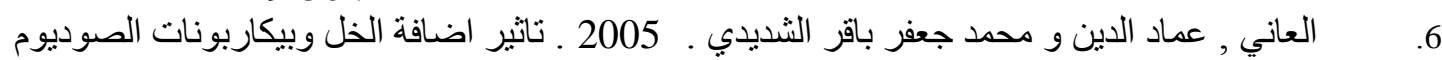

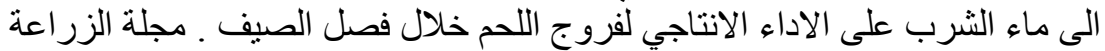

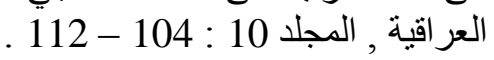

7.

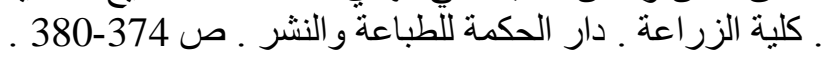

8. SAS .Institute(.2001).SAS/TAT . Guide for personal computers . version 6 Edition SAS Institute Inc Cary NC.

9. NRC National Research Council( 1994). Nutrient Requirements of Poultry. National Academy Press Washington DC. 
10. Guerrero R and Hoyos G (1990). Direct- feed microbials and acidifier for poultry . pp407-411. Alltch's $7^{\text {th }}$ Ann. Sym. On: Biotechnology In The Feed Industry . Longhborough, Leciershire USA.

11. North OM( 1984). Commercial Chicken Production Manual $3^{\text {rd }}$, ed. AVI Publishing company. Inc. Westport Connecticut.

12. Haninger RW Newcomer WS and Thayer RH(1960). The effect of eleveted ambiet temperature on the thyroxin in secretion on rate of chicken . Poultry Sci. 19 : 549-557

13. Thompson JL and Hinton M (1997) . Anti bacterial activity of formic and propionic acids in the diets of hens on Salmonella in corp. British Poultry Sci. 38: 59-65.

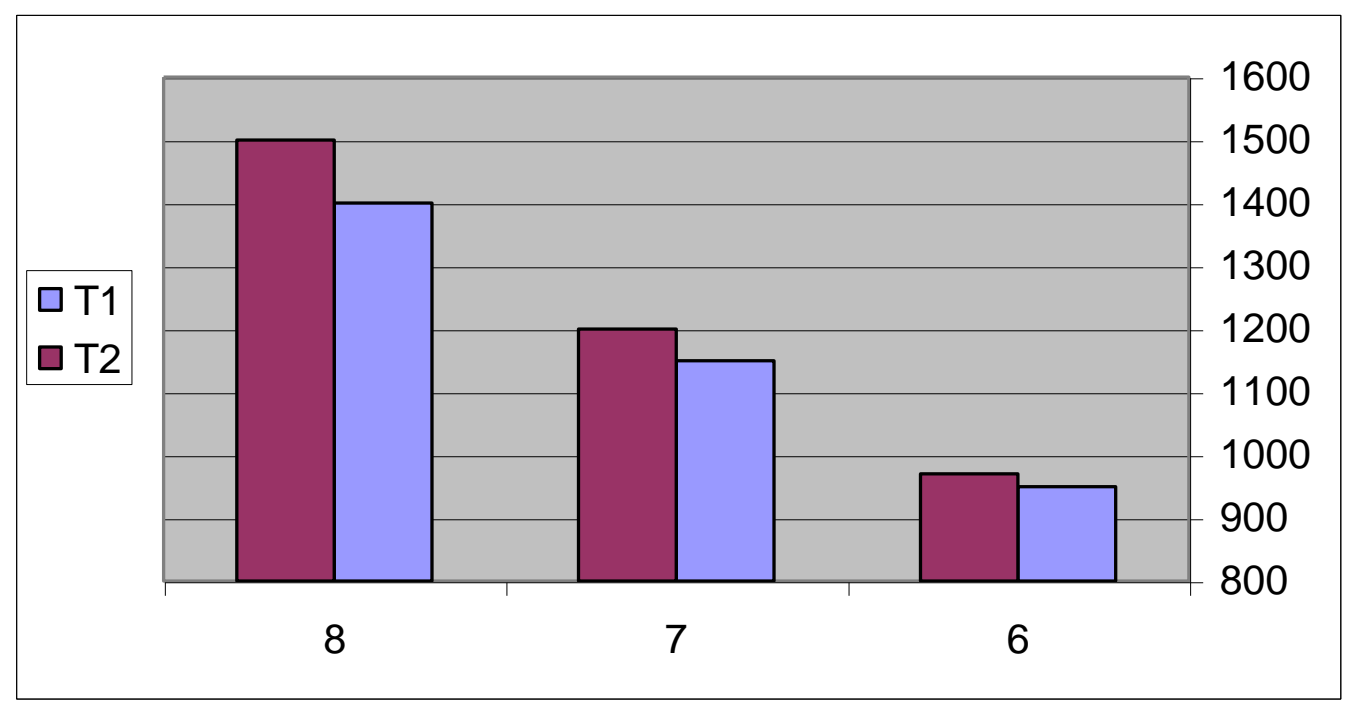

العمر (اسبوع ) معدال)

شكلى (1) تأثير اضافة الخل على معدل الوزن الحي لفروج اللحم (غم/طير)

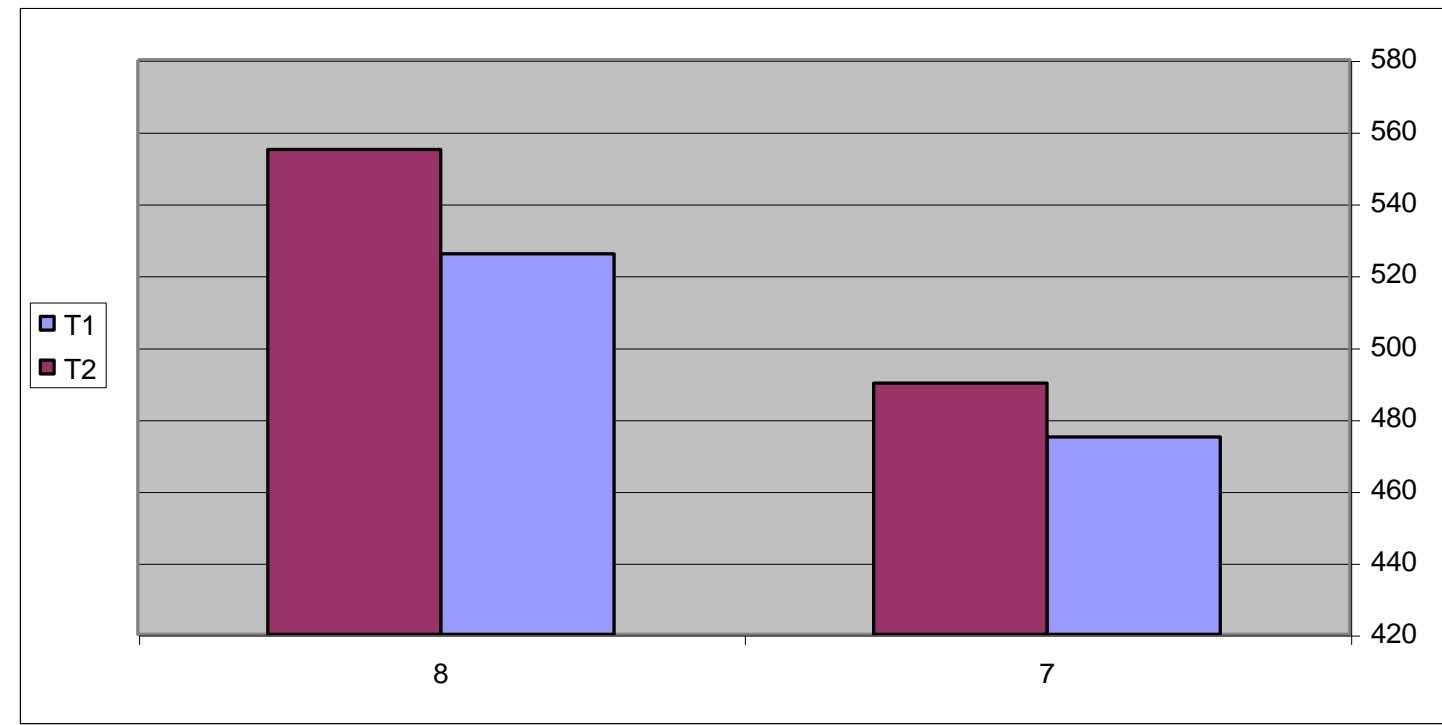

$$
\text { العمر (اسبوع ) }
$$

شكل (2) تأثير اضافة الخل على استهلاك العلف لفروج اللحم (غم / طير) 


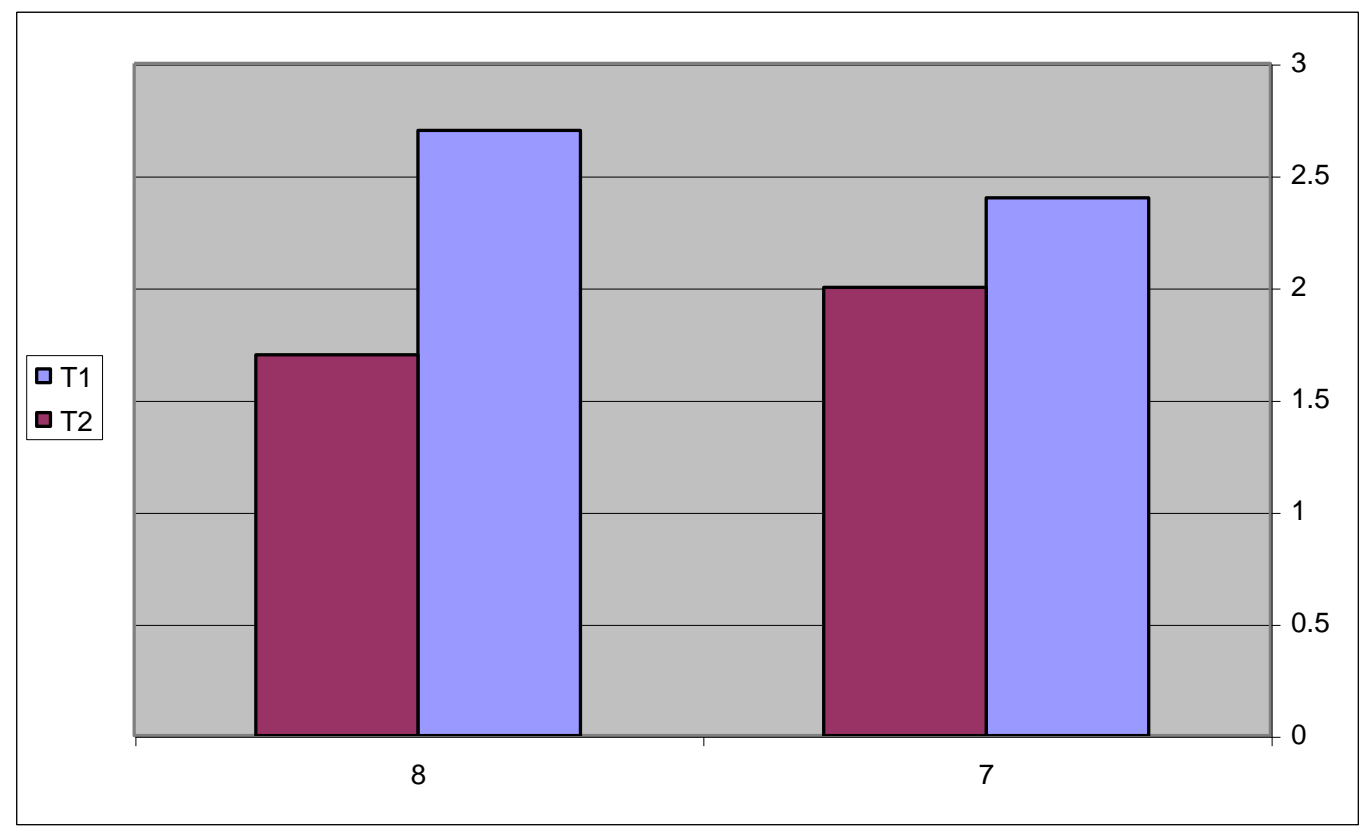

\section{العمر (اسبوع )}

شكل (3) نأثثر اضافة الخل على كفاءة التحويل الغذائي لفروج اللحم (غم علف / غم زيادة وزنية)

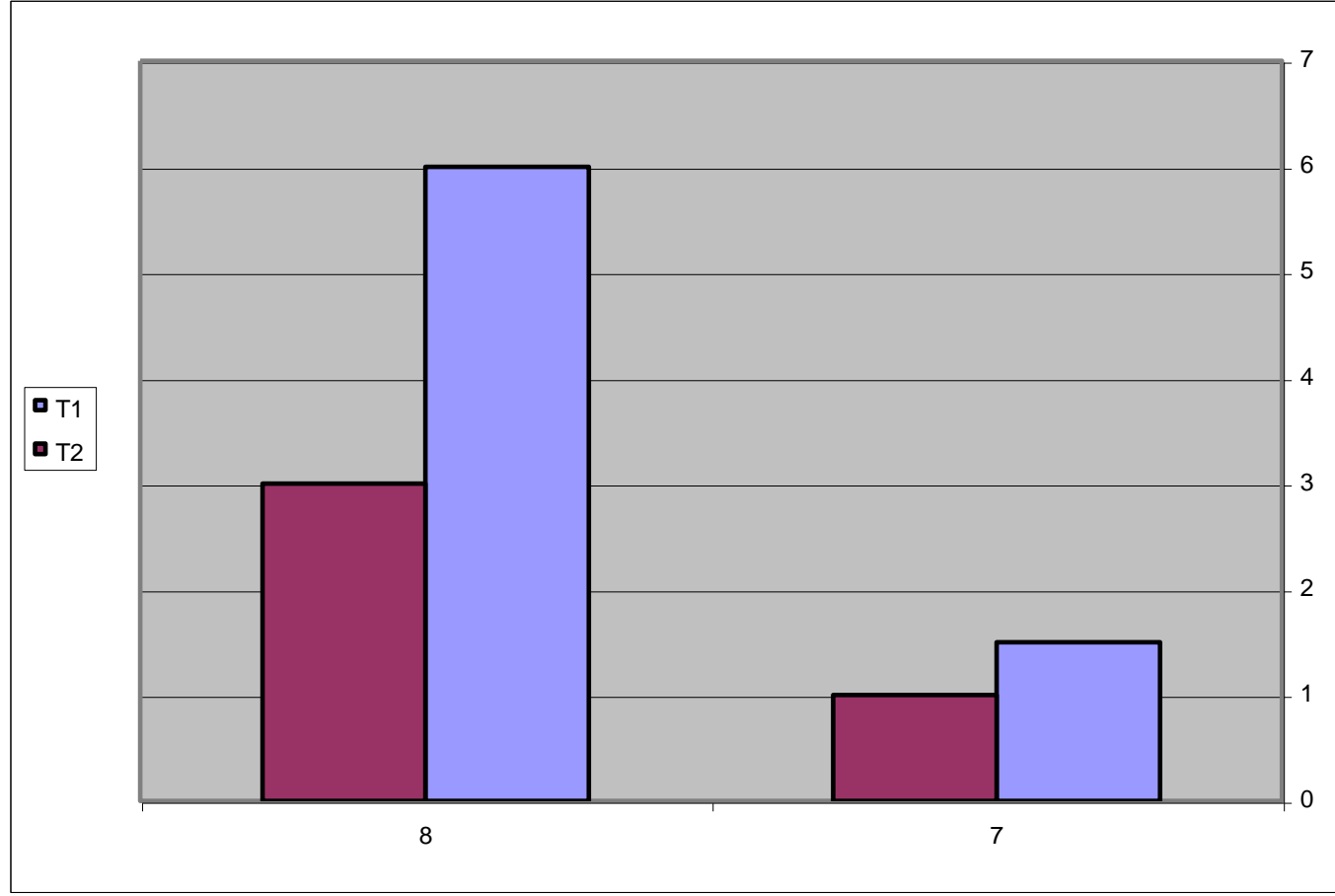

$$
\text { العمر (اسبوع) ) }
$$

شكل (4) تأثير اضافة الخل على النسبة المئوية لهلاكات فروج اللحم 